\title{
A Case for Montelukast in COVID-19: "The use of Computational Docking to estimate the effects of Montelukast on potential viral main protease catalytic site"
}

\section{Salman Mansoor ( $\sim$ salmanmansoor.dr@gmail.com )}

Department of Neurology, Sligo University Hospital, Sligo, Ireland https://orcid.org/0000-0001-55155972

\section{Shoab Saadat}

Department of Nephrology, Mid-essex Hospitals, NHS Trust, United Kingdom

\section{Aitzaz Amin}

Department of Medicine, Sligo University Hospital, Sligo, Ireland Imran Ali

Department of Rheumatology, Sligo University Hospital, Sligo, Ireland

\section{Muhammad Tauseef Ghaffar}

Department of Medicine, Sligo University Hospital, Sligo, Ireland

\section{Usman Amin}

Department of Rheumatology, Waterford University Hospital, Waterford, Ireland

\section{Mohsin Mukhtar}

Department of Endocrinology, St.Luke's Regional Hospital, Kilkenny, Ireland

\section{Research Article}

Keywords: Montelukast, Cytokine Storm, IL-6, Coronavirus, COVID-19, Computational Docking

Posted Date: May 21st, 2020

DOI: https://doi.org/10.21203/rs.3.rs-27079/v1

License: (a) (i) This work is licensed under a Creative Commons Attribution 4.0 International License. Read Full License 


\section{Abstract}

This article explores the possible role of Montelukast in management of SARS-CoV-2 infection after reviewing the available literature and further uses computational docking to estimate the effects of Montelukast on the main protease inhibitor site of SARS-CoV-2.

\section{Methodology:}

In this study, we used molecular docking to estimate the direct effects of Montelukast on the main protease (Mpro) inhibitor site of the SARS-CoV-2. While other studies have been performed on the homology models, we obtained the Mpro crystalized structure, A-chain (304 amino acid residues) from protein data bank (PDB code 5REK) for this analysis

\section{Results:}

The best docked Montelukast conformer had a mfscore of -71.68 and was seen to be making multiple hydrogen bonds with the neighbouring residues (T24, T24, T26, S46) with the closest bond with T24 (Distance= 1.71 angstrom). Important finding was its hydrogen bond with $\mathrm{H} 41$ and hydrophobic interactions with $\mathrm{C} 145$ as these residues for important members of the active catalytics site.

\section{Conclusion:}

The computational model which was used against the crystalized Mpro structure suggested a possible inhibitory role of Montelukast in binding to the Mpro catalytic site which may modulate and inhibit the viral replication.

\section{Introduction}

Montelukast has been used widely in treatment of Asthmatic patients since 1998 in the United States ${ }^{1}$. The mechanism of action of Montelukast has been due to its antagonistic effects on the leukotriene D4 receptors which relaxes smooth muscles in lungs and reduces inflammation ${ }^{1}$.

\section{COVID-19 Pandemic:}

World was taken by surprise when a novel Coronavirus related illness broke out in late 2019 in Wuhan province of China and later was declared as a Pandemic due to its global impact by World Health Organization $(\mathrm{WHO})^{2}$. Since then the illness has impacted the world which have been unprecedented with over a million people who have been affected. The mortality rate was reported to be $4 \%$ in China but it is observed to vary in different countries ${ }^{3}$.

\section{Immune Mechanism:}

The current literature in relation to the immunological response in SARS-CoV-2 is scarce. However, studies done in the past on Coronoviruses (CoVs) in particular SARS-CoV and MERS-CoV do bridge this 
knowledge gap. The host immune system after the viral entry recognizes this by pattern recognition receptors (PRRs) that include Toll like receptors (TLR), C-type lectin-like receptors, RIG-1 like receptors (RLR) AND NOD-like receptor (NLR) ${ }^{4}$. There are different pathways through which the virus induces expression of inflammatory markers that limits spread and accelerates macrophage phagocytosis of the viral antigens ${ }^{3,4}$. The viral N-Protein of SARS-CoV is linked to protect the virus against this immune assault ${ }^{4}$. CD4+T and CD8+ T cells play an important role in the host adaptive immune response whereby $\mathrm{CD} 4+\mathrm{T}$ cells stimulate the B-cells to in producing antibodies while CD8+T cells directly kill the virusinfected cells. The free radical injury to various organs is as a result of the hyper-exaggerated immune response specially lungs and may result in multi-organ failure and death ${ }^{5}$. This immune cascade is also termed as "cytokine storm".

The main difference from autopsy findings from other related diseases with cytokine storm was destruction of lymphoid tissue in SARS-COV- ${ }^{6}$. Low CD4+T cells and CD8+T cells on immunohistochemical staining were observed ${ }^{6}$. The characteristic finding in the lungs showed diffuse alveolar damage and infiltration of monocytes and macrophages ${ }^{6}$.

\section{Cytokine Storm:}

Cytokine storm was the term first used in 1993 in an article on graft-versus host disease but since 2005 after avian $\mathrm{H} 5 \mathrm{~N} 1$ influenza it has been widely used ${ }^{7}$. It has also been reported with infections related to cytomegalovirus, Epstein-Barr virus-associated hemophagocytic lymphohistiocytosis, group A streptococcus, influenza virus, variola virus, and severe acute respiratory syndrome coronavirus (SARSCoV) and SARS-CoV-2 ${ }^{8-12}$.

The SARS-Cov-2 is known to activate the innate and adaptive immune response by binding to ACE2 receptor ${ }^{13}$. The underlying systemic response in cytokine storm results in release of TNFa, IL-1 $\beta$, IL-2, IL-6, IFNa, IFN $\beta$, IFNy, and MCP-1 which result in production of free radicals from the immune cells causing hyper-permeability, end-organ damage and acute respiratory distress syndrome (ARDS) ${ }^{14}$.

\section{Montelukast Mechanism of Action:}

Montelukast is proposed to potentiate its effects through two probable mechanisms:

1. Its effect in preventing the cytokine storm by modulating the immune response

Montelukast acts on cysteinyl leukotriene 1 (CysLT1) receptor inhibiting tracheal contraction by inhibiting leukotriene $\mathrm{D} 4$ and $E 4{ }^{15}, 16$. Leukotrienes are proinflammatory cytokines which that are produced as a result of 5-Lipoxygenase pathway (5-LO) pathway ${ }^{17}$. The receptors for Leukotrienes are found in airways which bring about changes in relation to inflammation and spasm. Montelukast binds to these receptor sites to inhibit the action of proinflammatory cytokines ${ }^{18,19,20}$. 
In a septic shock model Montelukast was found to reduce the mortality by reducing the levels of TNF-a and IL-6 levels ${ }^{21}$. It increased the levels of lipid peroxidase and myeloperoxidase activity in lungs, liver and kidney ${ }^{21}$. This in turn protected against multiple organ failure secondary to systemic inflammatory response ${ }^{21}$.

The high dose administration of Montelukast was also found in asthmatic patients to mediate the levels of proinflammatory cytokines IL-6, TNFa and MCP-1 through the inhibition of NF- ${ }^{\mathrm{B}} \mathrm{B}$ activation ${ }^{22}$.

2. The direct effect on the virus which is explored using the computational docking.

\section{Montelukast Structure:}

The molecular formula for Montelukast is $\mathrm{C}_{35} \mathrm{H}_{36} \mathrm{CINO}_{3} \mathrm{~S}$ it belongs the quinolone group of compounds, monocarboxylic acid and an aliphatic sulphide as shown in Figure.1. It has a molecular weight of 586.2 $\mathrm{g} / \mathrm{mol}$ with a hydrogen bond donor count of 2 , hydrogen acceptor count of 5 , rotatable bond count of 12 the topological polar surface area of $95.7 \AA^{2} 23$.

\section{Computational Docking on potential viral main protease inhibitor site:}

\section{Background:}

During the current SARS-CoV-2 pandemic molecular docking techniques have taken a pivotal role in generating potential treatments. In order to find the most suitable drug for a given receptor, we usually use a computation method called docking by virtue of which we get to position a given drug in a given receptor site and calculate the binding affinities between the drug and the receptor pocket.

\section{Methodology}

The drug is initially prepared by adding the necessary hydrogen ions and electrostatic charges before placing it in the receptor pocket. A similar preparation is performed on the receptor pocket as well. Once prepared, the computer presents the drug to the pocket in several different 3 dimensional conformations and orientations using a probability based method (Monte Carlo procedure) and for each conformation, the binding affinities between the drug and receptor pocket are calculated using a selected force-field rules. The drug conformation with the highest binding affinity (or the lowest mfScore) is selected as the best ligand conformation.

In this study, we used molecular docking to estimate the direct effects of Montelukast on the main protease (Mpro) inhibitor site of the SARS-CoV-2. While other studies have been performed on the homology models, we obtained the Mpro crystalized structure, A-chain (304 amino acid residues) from protein data bank (PDB code 5REK) for this analysis ${ }^{24}$. This protein is essential for processing of polyproteins translated from the main viral RNA and acts on at least 11 cleavage sites on large polyprotein $1 A B$ inhibiting its activity is most likely to block the viral replication ${ }^{25}$. 
We then used computational methods (Internal Coordinate Mechanics pro version 3.7) to identify the most suitable drug binding pockets. Based on a transformation of the Lennard-jones potential by convolution with a gaussian kernel of a certain size, a grid map of binding potentials and construction of equipotential surfaces along the maps was carried out subsequently identifying the position and size of potential ligand binding pockets ${ }^{26,27}$.

There were a total of three candidate pockets along the protein surface which were identified. The selected pocket had a volume of $284 \AA^{3}$ and a surface area of $347 \AA^{2}$. The hydrophobicity ratio score was 0.43 with 1 being the maximum. By using biased probability Monte Carlo (BPMC) procedure which randomly selects a ligand conformation in the internal coordinate space and makes a step to a new random position independent of the previous one. The selected pocket happened to contain the most important residues ( $\mathrm{H} 41$ and $\mathrm{C} 145)$ involved in the active catalytic process of Mpro ${ }^{28}$.

\section{Results}

Montelukast was docked on to the selected pocket. The lowest potential of mean force score (mfScore) came out to be -71.68 with a hydrophobicity score of -7.9. Montelukast in docked position was neighboured by $\mathrm{T} 24, \mathrm{~T} 24, \mathrm{~T} 26, \mathrm{~S} 46, \mathrm{G} 143, \mathrm{H} 41, \mathrm{E} 166, \mathrm{Q} 189, \mathrm{~T} 25, \mathrm{P} 168, \mathrm{~N} 142, \mathrm{C} 145, \mathrm{M} 165, \mathrm{~L} 27, \mathrm{~T} 45$ in the ascending order of distance from the ligand. Montelukast was seen to be making multiple hydrogen bonds with the neighbouring residues $(\mathrm{T} 24, \mathrm{~T} 24, \mathrm{~T} 26, \mathrm{~S} 46)$ with the closest bond with $\mathrm{T} 24$ (Distance= 1.71 angstrom). Important finding was its hydrogen bond with $\mathrm{H} 41$ and hydrophobic interactions with C145 as these residues for important members of the active catalytics site ${ }^{28}$.

Shown in Figure. 2 and Figure. 3

\section{Discussion}

A computational homology model with drug repositioning reported Montelukast to bind with the active pocket of SARS-CoV2 which may inhibit viral replication and slow down the disease activity by its direct effect ${ }^{29}$. Another structure-based drug repositioning model also suggested Montelukast to bind to the terminal substrate-binding pocket on Mpro of the SARS-CoV-2 ${ }^{30}$. Our model was in agreement to the previous studies as it shows a good binding affinity with the selected receptor pocket though it may not be forming bonds with the exact same amino acid residues from the previous studies. This finding is important as we did this study on the actual x-ray resolved crystalized PDB structure of Mpro and were able to locate the most suitable binding site involved in active catalysis for the given drug.

\section{Conclusion}

The computational model which was used against the crystalized Mpro structure suggested a possible inhibitory role of Montelukast in binding to the Mpro catalytic site which may modulate and inhibit the viral replication. 


\section{Abbreviations}

SARS-CoV: Severe Acute Respiratory Syndrome Coronavirus

SARS-COV-2: Novel Severe Acute Respiratory Syndrome coronavirus

MERS-CoV: Middle East respiratory syndrome coronavirus

TNF-a: Tumor necrosis factor alpha

IL-6: Interleukin-6

IL-1ß: Interleukin-1 beta

IL-2: Interleukin-2

IL-6: Interleukin-6

IFNa: Interferon alpha

IFN $\beta$ : Interferon beta

IFNY: Interferon gamma

MCP-1: Monocyte chemoattractant protein-1

NF- 『B: Nuclear Factor kappa-light-chain-enhancer of activated B cells

\section{Declarations}

- $\quad$ Ethics approval and consent to participate : Not Applicable

- $\quad$ Consent to publish : Not Applicable

- $\quad$ Availability of data and materials

- $\quad$ Competing interests: All authors declare no competing interests

- $\quad$ Funding: No funding was received at any point

- $\quad$ Authors' Contributions: SM, SS, AA, IA, MTG,UA, MM were involved in writing of manuscript reviewing literature, analyzing data

- $\quad$ Acknowledgements: Not applicable

\section{References}

1. "Montelukast Sodium Monograph for Professionals". Drugs.com. AHFS.

2. https://www.who.int/csr/don/12-january-2020-novel-coronavirus-china/en/

3. Spychalski P, Błażyńska-Spychalska A, Kobiela J (March 2020). "Estimating case fatality rates of COVID-19". The Lancet. Infectious Diseases. 
4. Lu X, Pan J, Tao J, Guo D. SARS-CoV nucleocapsid protein antagonizes IFN-beta response by targeting initial step of IFN-beta induction pathway, and its C-terminal region is critical for the antagonism. Virus Genes. 2011; 42: 37-45.

5. Channappanavar R, Perlman S. Pathogenic human coronavirus infections: causes and consequences of cytokine storm and immunopathology. Seminars in Immunopathology. 2017; 39: 529-39.

6. Qin C, Zhou L, Hu Z, Zhang S, Yang S, Tao Y, et al. Dysregulation of immune response in patients with COVID-19 in Wuhan, China. Clin Infect Dis. 10.1093/cid/ciaa248

7. Ben Addi A, Lefort A, Hua X, Libert F, Communi D, Ledent C, et al. Modulation of murine dendritic cell function by adenine nucleotides and adenosine: involvement of the $A(2 B)$ receptor. European journal of immunology. 2008; 38: 1610-20.

8. Ferrara JL, Abhyankar S, Gilliland DG. 1993. Cytokine storm of graft versus-host disease: a critical effector role for interleukin-1. Transplant. Proc. 25:1216 -1217.

9. Barry SM, Johnson MA, Janossy G. 2000. Cytopathology or immunopathology? The puzzle of cytomegalovirus pneumonitis revisited. Bone Marrow Transplant. 26:591-597.

10. Imashuku S. 2002. Clinical features and treatment strategies of Epstein-Barr virus-associated hemophagocytic lymphohistiocytosis. Crit. Rev. Oncol. Hematol. 44:259 -272.

11. Bisno AL, Brito MO, Collins CM. 2003. Molecular basis of group A streptococcal virulence. Lancet Infect. Dis. 3:191-200.

12. Yokota S. 2003. Influenza-associated encephalopathy-pathophysiology and disease mechanisms. Nippon Rinsho. 61:1953-1958.

13. Zhang C, Wu Z, Li JW, Zhao H, Wang GQ. The cytokine release syndrome (CRS) of severe COVID-19 and Interleukin-6 receptor (IL-6R) antagonist Tocilizumab may be the key to reduce the mortality. Int J Antimicrob Agents. 10.1016/j.ijantimicag.2020.105954

14. Tisoncik JR, Korth MJ, Simmons CP, Farrar J, Martin TR, Katze MG. Into the eye of the cytokine storm. Microbiol Mol Biol Rev. 2012; 76: 16-32.

15. Lynch KR, O'Neill GP, Liu Q, et al. Characterization of the human cysteinyl leukotriene CysLT1 receptor. Nature. 1999;399:789 - 793.

16. Figueroa DJ, Breyer RM, Defoe SK, et al. Expression of the cysteinyl leukotriene 1 receptor in normal human lung and peripheral blood leukocytes. Am J Respir Crit Care Med. 2001;163:226 -233.

17. Samuelsson B. Leukotrienes: mediators of immediate hypersensitivity reactions and inflammation. Science. 1983 May 6;220(4597):568-75.

18. Zhang L, Lasmar LB, Castro-Rodriguez JA. The impact of asthma and its treatment on growth: an evidence-based review. J Pediatr (Rio J). 2019 Mar - Apr;95 Suppl 1:10-22.5.

19. Castro-Rodriguez JA, Rodriguez-Martinez CE, Ducharme FM. Daily inhaled corticosteroids or montelukast for preschoolers with asthma or recurrent wheezing: A systematic review. Pediatr. Pulmonol. 2018 Dec;53(12):1670-1677. 
20. Hoffman BC, Rabinovitch N. Urinary Leukotriene $\mathrm{E}_{4}$ as a Biomarker of Exposure, Susceptibility, and Risk in Asthma: An Update. Immunol Allergy Clin North Am. 2018 Nov;38(4):599-610.

21. Coskun AK, Yigiter M, Oral A, Odabasoglu F, Halici Z, Mentes O, et al. The Effects of Montelukast on Antioxidant Enzymes and Proinflammatory Cytokines on the Heart, Liver, Lungs, and Kidneys in a Rat Model of Cecal Ligation and Puncture-Induced Sepsis. The Scientific World JOURNAL. 2011;11:1341-56.

22. Maeba S, Ichiyama T, Ueno Y, Makata H, Matsubara T, Furukawa S. Effect of montelukast on nuclear factor KB activation and proinflammatory molecules. Annals of Allergy, Asthma \& Immunology. 2005 Jun;94(6):670-4.

23. https://pubchem.ncbi.nlm.nih.gov/compound/Montelukast\#section=Chemical-and-PhysicalProperties

24. Anand, J. Ziebuhr, P. Wadhwani, J. R. Mesters, R. Hilgenfeld, Coronavirus main proteinase (3CLpro) structure: Basis for design of anti-SARS drugs. Science 300, 1763-1767 (2003). doi:10.1126/science.1085658pmid:12746549

25. An, J., Totrov, M. \& Abagyan, R. Pocketome via comprehensive identification and classification of ligand binding envelopes. Mol. Cell. Proteomics 4, 752 (2005).

26. Abagyan, R. \& Kufareva, I. The flexible pocketome engine for structural chemogenomics. Methods Mol. Biol. Clifton NJ 575, 249.279 (2009).

27. Abagyan R, Totrov M. Biased probability Monte Carlo conformational searches and electrostatic calculations for peptides and proteins. J Mol Biol. 1994 Jan 21;235(3):983-1002.

28. https://onlinelibrary.wiley.com/doi/pdf/10.1002/minf.202000028

29. Wu C, Liu Y, Yang Y, Zhang P, Zhong W, Wang Y, et al. Analysis of therapeutic targets for SARS-CoV-2 and discovery of potential drugs by computational methods. Acta Pharmaceutica Sinica B. 2020 Feb

30. https://chemrxiv.org/articles/Identification_of_FDA_Approved_Drugs_Targeting_COVID19_Virus_by_Structure-Based_Drug_Repositioning/12003930

\section{Figures}




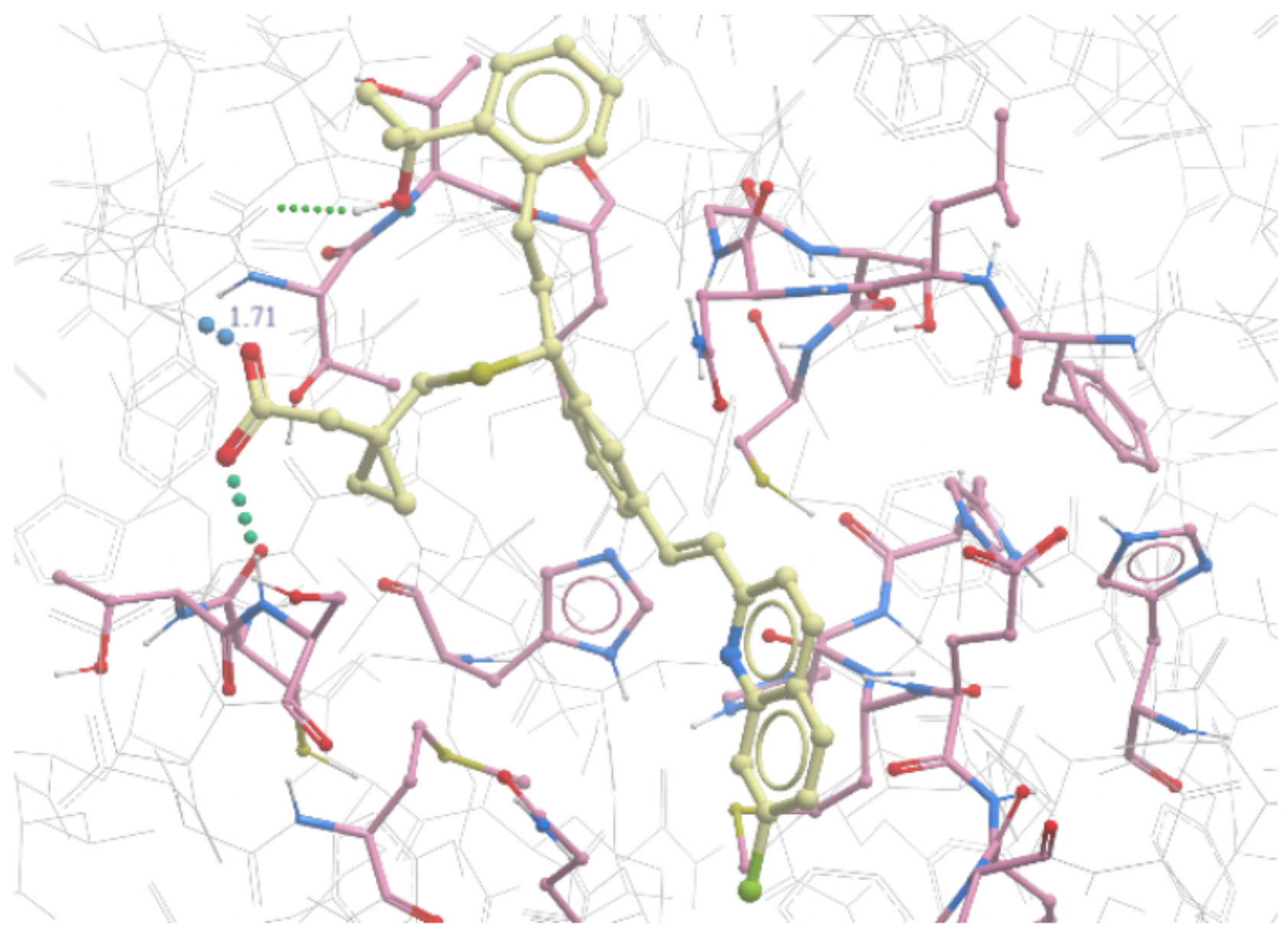

Figure 1

The molecular Structure of Montelukast 


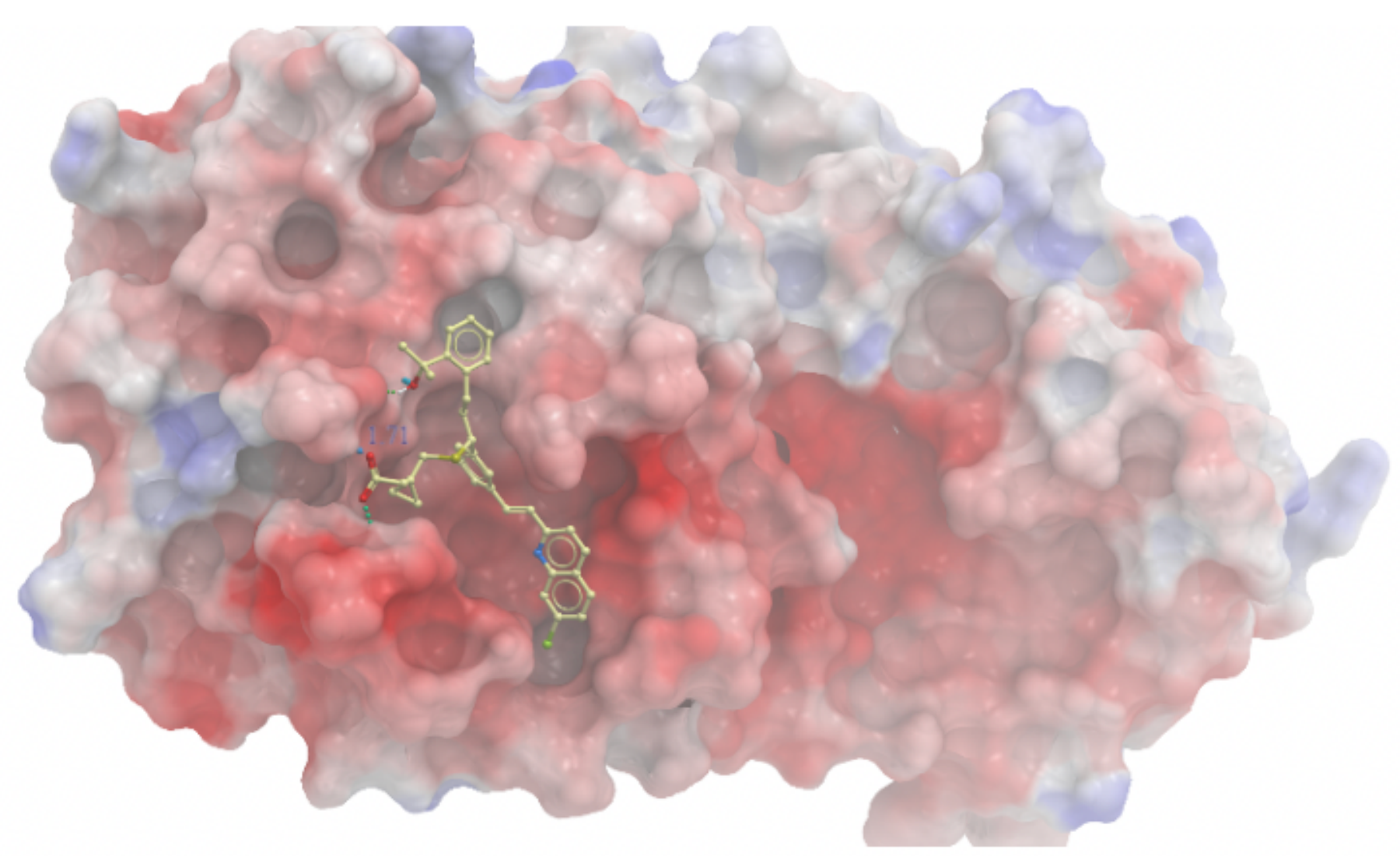

Figure 2

Montelukast docked into the receptor pocket of main protease (The Closest hydrogen bound between Montelukast and nearby residue has a distance of $1.71 \mathrm{~A}$ ) 


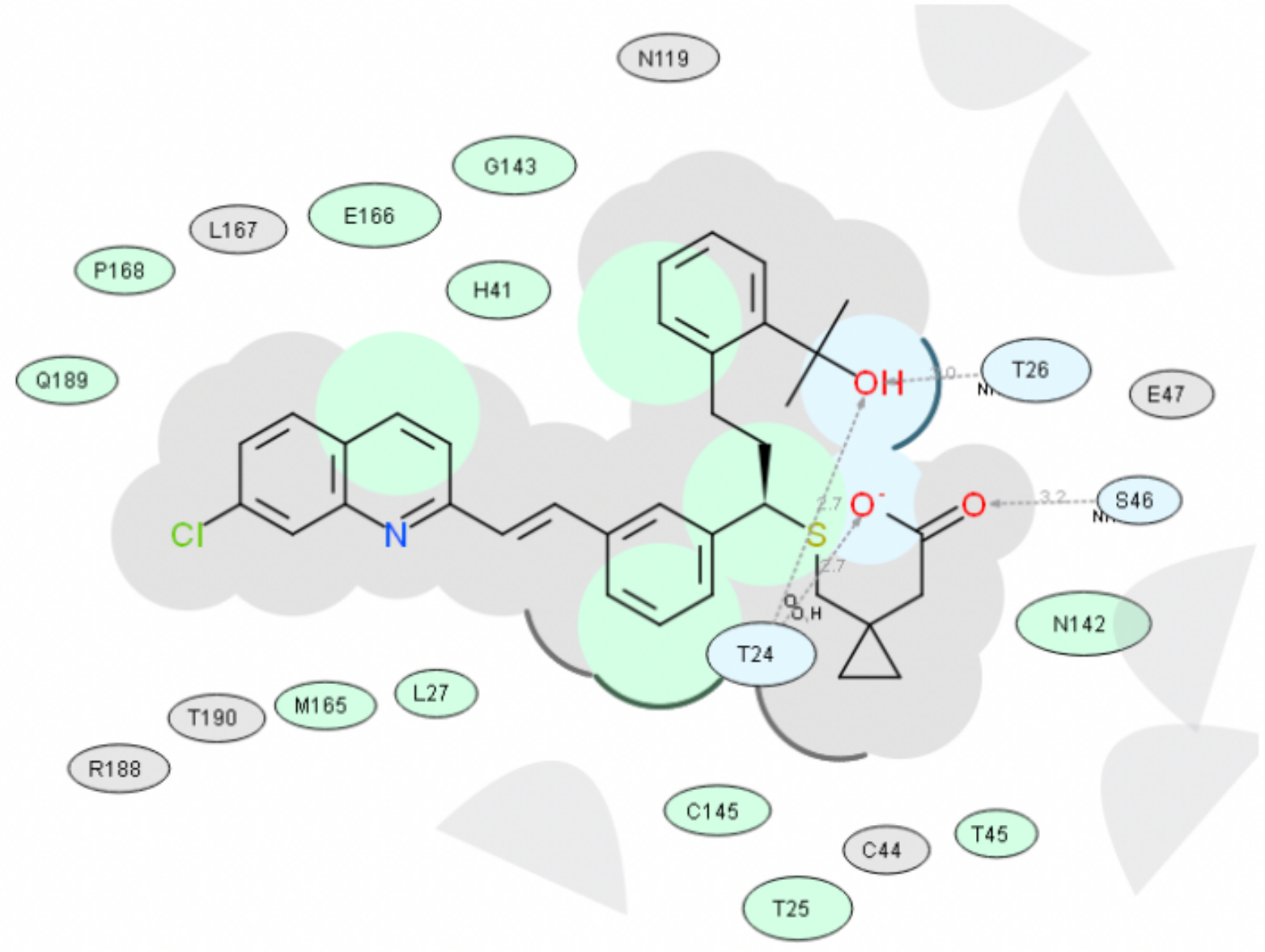

Figure 3

Dendogram of montelukast with neighbouring residues. Blue circles represent the hydrogen bond forming molecules while green circles represent hydrophobic interactions. 